\section{Staphylococcus intermedius infections: case report and literature review}

\author{
Nancy Wang,, ${ }^{1,2}$ Anne M. Neilan, ${ }^{3}$ \\ Michael Klompas 1,3,4,5,6
}

'Department of Neurology, Brigham and

Women's Hospital, Boston, MA;

2Department of Neurology,

Massachusetts General Hospital, MA;

${ }^{3}$ Division of Infectious Diseases, Brigham

and Women's Hospital, Boston, MA;

${ }^{4}$ Department of Infectious Diseases,

Massachusetts General Hospital Boston,

MA; ${ }^{5}$ Infection Control Department,

Brigham and Women's Hospital, Boston,

MA; 'Department of Population Medicine,

Harvard Medical School and Harvard

Pilgrim Health Care Institute, Boston, MA, USA

\section{Abstract \\ Staphylococcus intermedius is part of the normal skin and oral flora of dogs. Case reports of human infections are rare, but the true inci- dence is unknown because the pathogen is fre- quently misidentified as Staphylococcus aureus. Reported cases range from soft tissue infections to brain abscess. Most reported cases in humans have been related to dog exposure. We report a case of a 73 year old female with $S$. intermedius surgical wound infection one month following a left elbow total arthroplasty. This is the first reported human case of $S$. intermedius infection of a mechani- cal prosthesis. The presumed source of infec- tion was the patient's dog. The patient was treated with vancomycin, then switched to cefazolin and rifampin once susceptibilities were known. Case reports suggest that patients generally respond well to tailored antibiotics with complete or near-complete recovery. $S$. intermedius should be included in the differential diagnosis of invasive infection amongst patients with close contact with dogs.}

\section{Introduction}

Staphylococcus intermedius was first described in 1976 as a coagulase-positive Staphylococcus. It has since been identified as part of normal skin and mucosal flora in a variety of animals, including dogs, cats, pigeons, minks, horses, foxes, raccoons, goats, and gray squirrels. ${ }^{1}$ It is the predominant cause of skin and soft tissue infection in dogs, ${ }^{2-6}$ but has only rarely been isolated from humans. However, there are an increasing number of case reports documenting serious invasive infections with $S$. intermedius in humans including infected dog bite wounds, ${ }^{4,7-11}$ bacteremia, ${ }^{1}$ pneumonia, ${ }^{12}$ sinusitis, ${ }^{13}$ otitis externa, ${ }^{14}$ nail bed infection, ${ }^{15}$ mastoiditis, ${ }^{16}$ brain abscess, ${ }^{17}$ skin abscess, ${ }^{18}$ and bacteremia complicated by septic arthritis and iliacus abscess. ${ }^{19}$ There has also been one reported outbreak of $S$. intermedius related food intoxication involving over 265 cases in the western United States in $1991 .{ }^{20}$ More recently, the discovery of Staphylococcus pseudintermedius in 2005 has led to the reclassification of isolates formerly identified as $S$. intermedius based on molecular techniques. ${ }^{21}$ The $S$. intermedius group (SIG) was divided into $S$. intermedius, $S$. pseudintermedius, and Staphylococcus delphini. ${ }^{22}$ According to this new grouping, $S$. pseudintermedius, and not $S$. intermedius, is the species that colonizes and causes infections in dogs and cats, and $S$. intermedius mainly colonizes pigeons. ${ }^{22,23}$ Thus, older reports of $S$. intermedius, particularly in animal bites, are often now viewed as $S$. pseudintermedius. ${ }^{24}$

Because human infection with coagulase positive Staphylococci other than $S$. aureus is rare, pitfalls in identification of SIG organisms abound. The true incidence of SIG infections is unknown but likely higher than reported since laboratories tend to presumptively identify coagulase-positive Staphylococci as $S$. aureus. ${ }^{1}$ Additionally, $S$. intermedius has been falsely identified as MRSA on the basis of the phenotypic PB2 latex agglutination test which has otherwise good performance for detection of methicillin resistant $S$. aureus and coagulase negative Staphylococci..$^{15}$ Talan et al. found that $100 \%$ of $S$. aureus isolates were coagulase positive at 4 hours compared to only $26 \%$ of $S$. intermedius isolates. ${ }^{4}$ Thus, microbiology personnel should suspect SIG when coagulase tests proceed more slowly than normal and there is high clinical suspicion, such as history of an animal bite. The presence of SIG can then be confirmed through additional biochemical tests: SIG is pyrrolidonyl arylamidase and $\beta$-galactosidase positive in contrast to S.aureus. ${ }^{4,25}$ More recently, Sasaki et al. found that $S$. intermedius can be chemically distinguished from $S$. pseudintermedius by positive arginine dihydrolase and acid production from beta-gentiobiose and Dmannitol. ${ }^{22}$ The two species can also be distinguished using molecular and genetic testing, as well as MALDI-TOF mass spectrometry, although this is not commonly done. ${ }^{24,26}$

\section{Case Report}

A 73 year old Caucasian female with a history of severe osteoarthritis developed fever, pain,
Correspondence: Nancy Wang, Department of Neurology, Brigham and Women's Hospital, 75 Francis St, Boston, MA 02115, USA.

Tel. +1.617.7327432 - Fax: +1.617.7326083.

E-mail: nwang6@partners.org

Key words: Staphylococcus intermedius, pseudintermedius, infection, human.

Conflict of interests: the authors declare no potential conflict of interests.

Received for publication: 1 July 2012 .

Revision received: 25 August 2012.

Accepted for publication: 18 October 2012.

This work is licensed under a Creative Commons Attribution NonCommercial 3.0 License (CC BYNC 3.0).

(C) Copyright. Wang et al., 2013

Licensee PAGEPress, Italy

Infectious Disease Reports 2013; 5:e3

doi:10.4081/idr.2013.e3

redness, and swelling of her left elbow one month following a revision left elbow total arthroplasty. The original arthroplasty 10 years earlier had been complicated by infection that was successfully treated with several weeks of intravenous antibiotics according to the patient; the details of this remote infection and treatment were unattainable. She was subsequently well for many years without antibiotics until about 2 years prior to presentation when she began to develop gradually progressive joint instability and pain. She was admitted for elective total arthroplasty of the left elbow. Following surgery, she noted continuous serosanguinous drainage. Her orthopedist aspirated the joint on post-operative day 22 . The joint fluid was described as cloudy with 26,000 red blood cells, 1300 white blood cells and $31 \%$ neutrophils. No organisms were seen on Gram stain, and bacterial cultures were negative. Patient was not started on antibiotics at this time. A few days later (post-operative day 25) she developed progressive elbow pain and fever and was admitted to the hospital. On admission, her temperature was $102.2^{\circ} \mathrm{F}$ and her white blood cell count was 11,000 cells/ $/ \mathrm{mm}^{3}$.

On surgical exploration, a large fluid collection was found in the elbow. The joint capsule appeared intact, however both wound and joint fluid cultures grew $S$. intermedius, as identified by the Vitek II automated microbiology system without further subspeciation. The wound was irrigated but the elbow prosthesis was not removed. Blood cultures were negative. In accordance with CLSI standards, the elbow isolates were determined to be resistant to penicillin and tetracycline but susceptible to oxacillin, erythromycin, clindamycin, chloram- 
要

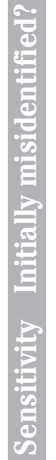

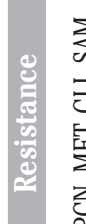

要

충

๘

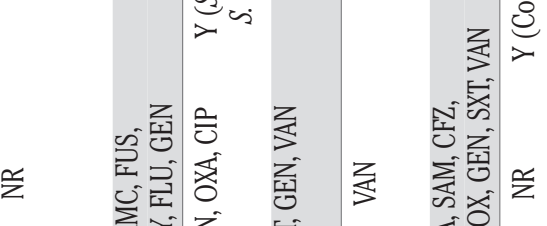

存文

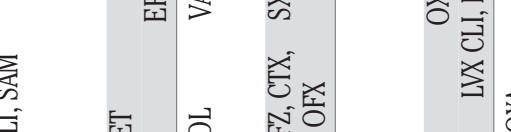

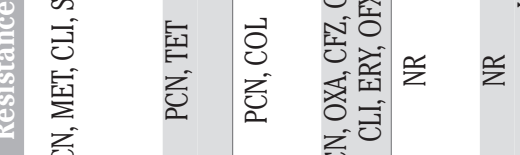

ट̇

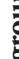

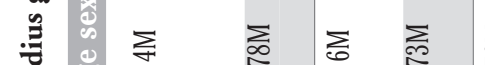

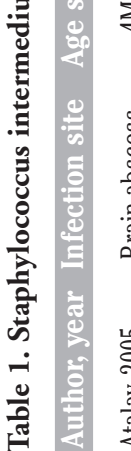




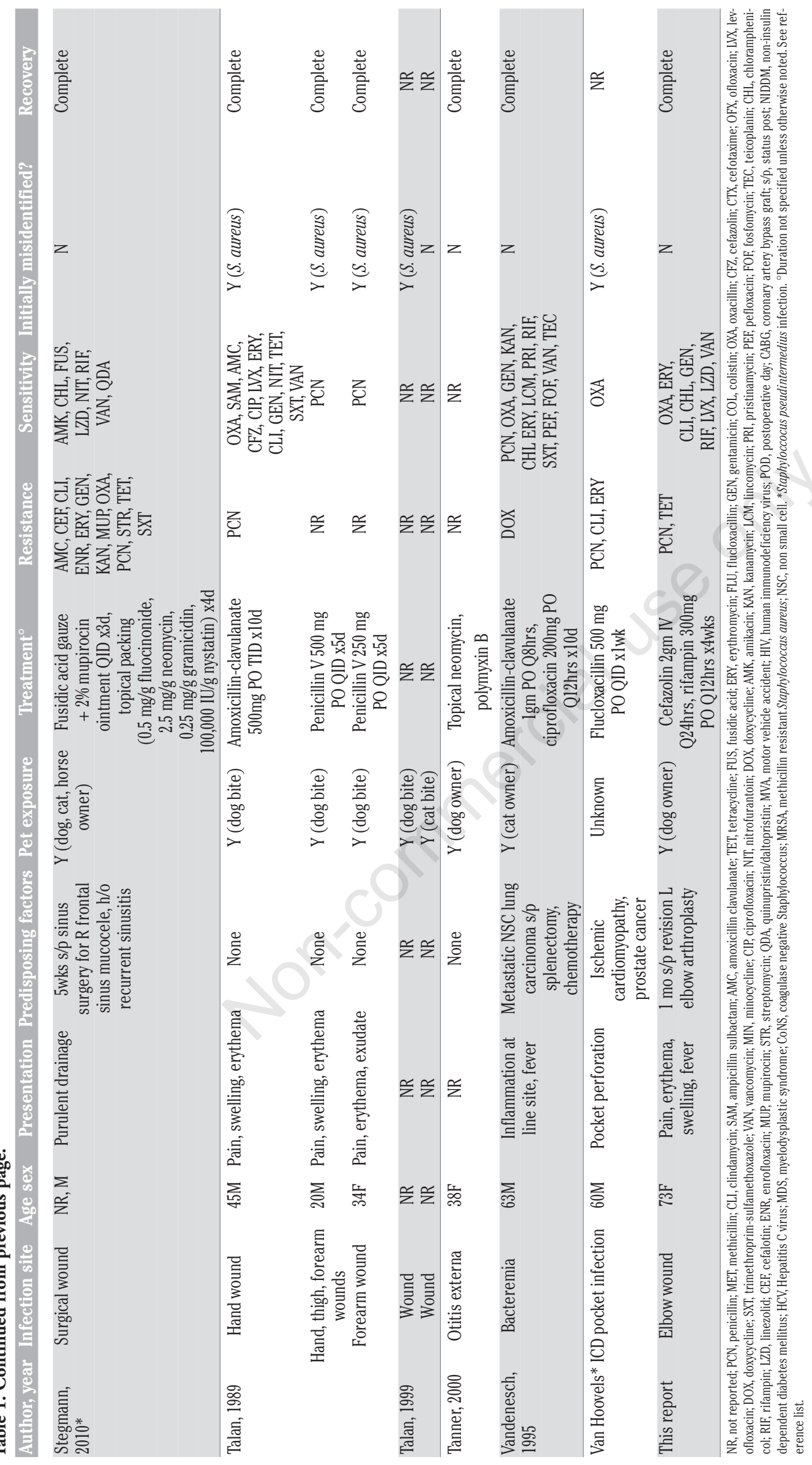


phenicol, gentamicin, rifampin, levofloxacin, linezolid, and vancomycin. The patient was treated with intravenous cefazolin and rifampin for six weeks and then transitioned to oral levofloxacin and rifampin with plan for a prolonged course given retention of infected prosthesis. She has not had any recrudescence of disease after 10 months on this regimen and will be reevaluated for possible cessation of therapy at one year's time.

The patient was an avid dog lover. Although she did not recall her dog licking or biting her elbow after surgery, she did report that her dog frequently licked her face. She admitted to frequent close contact with her dog including sharing her bed at night. She denied any recent illness or skin lesions in her dog.

\section{Discussion}

Human SIG infections are rarely reported. We conducted a literature review by searching PubMed using the terms Staphylococcus intermedius, $S$. intermedius, Staphylococcus delphini, Staphylococcus pseudintermedius, infection and human. References cited in these articles were also examined. Only articles published in English were reviewed, and only invasive infections were included in this discussion. The documented outbreak of $S$. intermedius related food-borne illness was excluded as additional clinical information on the individual cases was not available.

We found 17 published articles documenting 29 SIG infections in humans, 25 with $S$. intermedius and 4 with $S$. pseudintermedius. There were no published cases of $S$. delphini in humans. All 29 cases are outlined in Table 1, with asterisks marking cases of $S$. pseudintermedius. Notably, $S$. intermedius and $S$. pseudintermedius were initially misidentified as $S$. aureus in 34\% of 29 cases. Seven of 29 cases (24\%) were reported to be polymicrobial by Gram stain, culture, or PCR restriction fragment length polymorphism. Four of the seven polymicrobial cases occurred in dog bite wounds, and one occurred in a patient with known dog exposure.

$S$. intermedius was first described as a human pathogen in dog bite wounds by Talan in $1989 .{ }^{4}$ Overall, 23 of the 29 (79\%) of reported cases involved dog bites (11 cases), cat bites (one case), or dog or cat exposure without documented bites (11 cases). ${ }^{8-11,19,27-29}$ The rate of $S$. intermedius infection in dog bite infection case series ranged from two to $21 \%{ }^{10,11}$ Three of the 11 cases in patients without documented bites but with dog or cat exposure were delayed surgical site infections: one case of sinusitis eight months after a transsphenoidal resection of a pituitary adenoma, one case of mastoiditis seven years after a mastoidectomy, and one case of a surgical wound infection five weeks after sinus surgery. ${ }^{13,16,27}$ These cases suggest that alteration of local host defenses may be a risk factor for inoculation without a bite.

Six of the 29 cases (21\%) in this series occurred in patients without known animal exposures suggesting that humans can carry this organism in the absence of animal pressure..$^{12,15,17,18,30}$ In one case, an intravenous cocaine user accustomed to licking his syringe prior to injection developed skin abscesses. ${ }^{18}$ Notably, screening series have variously found

Table 2. Antibiotic susceptibilities across cases reviewed.

\begin{tabular}{|c|c|c|}
\hline & Isolates tested & Isolates susceptible (\%) \\
\hline $\begin{array}{l}\text { Aminoglycosides } \\
\text { Amikacin } \\
\text { Erythromycin } \\
\text { Gentamicin } \\
\text { Kanamycin } \\
\text { Streptomycin }\end{array}$ & $\begin{array}{c}23 \\
1 \\
10 \\
10 \\
1 \\
1\end{array}$ & $\begin{array}{c}18(78 \%) \\
0(0 \%) \\
7(70 \%) \\
10(100 \%) \\
1(100 \%) \\
0(0 \%)\end{array}$ \\
\hline $\begin{array}{l}\text { Cephalosporins } \\
\text { Cefazolin } \\
\text { Cefotaxime }\end{array}$ & $\begin{array}{l}8 \\
7 \\
1\end{array}$ & $\begin{array}{l}5(63 \%) \\
5(71 \%) \\
0(0 \%)\end{array}$ \\
\hline $\begin{array}{l}\text { Glycopeptides } \\
\text { Teicoplanin } \\
\text { Vancomycin }\end{array}$ & $\begin{array}{c}12 \\
1 \\
11\end{array}$ & $\begin{array}{r}12(100 \%) \\
1(100 \%) \\
11(100 \%)\end{array}$ \\
\hline $\begin{array}{l}\text { Lincosamides } \\
\text { Clindamycin } \\
\text { Lincomycin } \\
\text { Penicillins } \\
\text { Amoxicillin-clavulanate } \\
\text { Ampicillin-sulbactam } \\
\text { Flucloxacillin } \\
\text { Methicillin } \\
\text { Oxacillin } \\
\text { Penicillin }\end{array}$ & $\begin{array}{c}10 \\
9 \\
1 \\
35 \\
4 \\
5 \\
1 \\
2 \\
10 \\
13\end{array}$ & $\begin{array}{l}7(70 \%) \\
6(66 \%) \\
1(100 \%) \\
22(63 \%) \\
4(100 \%) \\
4(80 \%) \\
1(100 \%) \\
1(50 \%) \\
8(80 \%) \\
4(31 \%)\end{array}$ \\
\hline $\begin{array}{l}\text { Quinolones } \\
\text { Ciprofloxacin } \\
\text { Levofloxacin } \\
\text { Ofloxacin } \\
\text { Pefloxacin }\end{array}$ & $\begin{array}{l}14 \\
5 \\
7 \\
1 \\
1\end{array}$ & $\begin{array}{l}12(86 \%) \\
5(100 \%) \\
6(86 \%) \\
0(0 \%) \\
1(100 \%)\end{array}$ \\
\hline $\begin{array}{l}\text { Streptogramins } \\
\text { Pristinamycin } \\
\text { Quinupristin/dalfopristin }\end{array}$ & $\begin{array}{l}2 \\
1 \\
1\end{array}$ & $\begin{array}{l}1(50 \%) \\
1(100 \%) \\
0(0 \%)\end{array}$ \\
\hline $\begin{array}{l}\text { Tetracyclines } \\
\text { Doxycycline } \\
\text { Minocycline } \\
\text { Tetracycline } \\
\end{array}$ & $\begin{array}{l}9 \\
2 \\
1 \\
6\end{array}$ & $\begin{array}{l}4(44 \%) \\
1(50 \%) \\
1(100 \%) \\
2(33 \%)\end{array}$ \\
\hline $\begin{array}{l}\text { Other } \\
\text { Chloramphenicol } \\
\text { Colistin } \\
\text { Fosfomycin } \\
\text { Fusidic acid } \\
\text { Linezolid } \\
\text { Mupirocin } \\
\text { Nitrofurantoin } \\
\text { Rifampin } \\
\text { Trimethoprim-sulfamathoxazole }\end{array}$ & $\begin{array}{l}2 \\
1 \\
1 \\
1 \\
1 \\
1 \\
3 \\
3 \\
8\end{array}$ & $\begin{array}{l}2(100 \%) \\
0(0 \%) \\
1(100 \%) \\
1(100 \%) \\
1(100 \%) \\
1(100 \%) \\
3(100 \%) \\
3(100 \%) \\
7(88 \%)\end{array}$ \\
\hline
\end{tabular}

Method of susceptibility testing was not reported in 11 of 17 articles reviewed. Reported methods included the automated Vitek system, Phoenix automated system, disc diffusion testing, manual dilution testing. Only two published reports referenced CLSI guidelines.
S. intermedius in five of $56(9 \%)$ human subjects' oral flora, and five of 17 (29\%) subjects' skin flora. ${ }^{31,32}$ Nonetheless, other staphylococcal species are much more common: $S$. intermedius constituted only 23 of 375 staphylococcal isolates from the skin of 17 individuals. ${ }^{32}$

Interestingly, regular contact with animals in and of itself does not appear to increase the rate of colonization. Talan et al. only found $S$. intermedius in the nasopharyngeal flora of one out of 144 healthy veterinary workers. ${ }^{33}$ Similar studies on $S$. pseudintermedius have detected the methicillin-resistant strain of the organism 
in $3-5 \%$ of samples from owners of pets with recent $S$. intermedius clinical infection and seven of $128(5 \%)$ veterinarians. ${ }^{34-36}$ There are data, however, to suggest that transient increases in dogs' bacterial load may increase the risk of transmission to humans. Guardabassi et al. found antimicrobial-resistant $S$. intermedius strains in six of 13 dog owners whose pets were being treated for pyoderma. ${ }^{37}$ The owners' strains were mostly identical to those found in their dogs. However, $S$. intermedius was no longer present in these same dog owners two months later, suggesting that human acquisition might be transiently related to increased colonization pressure or antibiotic exposure when their pets are acutely ill.

Only three pet-related cases confirmed matching $S$. intermedius strains between patient and dog via pulse field gel electropheresis and PCR restriction fragment length polymorphism. In two of the cases, the patient reported a history of dog licks at the site of infection. Our patient did not recall any episodes of her dog licking her wound, but transmission could have occurred through direct inoculation of the wound from contact with her dog's skin or indirectly through colonization of the patient followed by invasion of the wound ${ }^{3}$

Treatment of SIG infections in humans has been largely directed by the site of infection and antibiotic susceptibilities. In the cases reviewed, treatment courses ranged from four days of topical antibiotics for otitis externa to eight weeks of intravenous antibiotics for brain abscess. ${ }^{14,17}$ Susceptibility patterns are documented in Table 2. Three reports performed testing for the mecA gene, with three of four cases being negative. ${ }^{15,27,30}$ Guardabassi et al. suggest that pets may facilitate the spread of resistance genes, serving as reservoirs, and resistance patterns in human infections may reflect increasing use of antibiotics in pets..$^{37}$ In all except one case, patients had complete recovery after treatment: one individual with a $S$. intermedius brain abscess reported minor residual hemiparesis following antibiotic treatment but no recrudescent infection. ${ }^{17}$ Our patient is the first reported case of mechanical prosthesis infection. Despite retention of prosthesis, our patient has been clinically well thus far following six weeks of induction therapy with cefazolin and rifampin followed by 10 months of oral levofloxacin and rifampin to date.

\section{Conclusions}

To the best of our knowledge, this is the first reported human case of mechanical prosthesis infection with a SIG organism, the second reported case of infection in the immediate post-operative period, and only the fourth case of a SIG post-surgical wound infection. The actual incidence may be higher due to misidentification of $S$. intermedius and $S$. pseudintermedius as $S$. aureus. Immune status does not appear to be a factor in SIG infection, and infections can be monomicrobial or polymicrobial. Overall, infections seem to respond well to therapy guided by susceptibility tests. The possibility of direct transmission of a pathogenic organism from a pet to a postsurgical wound suggests that surgical patients may need to be warned to limit direct contact with pets, particularly dogs, during recovery. However, more studies confirming matching strains between pets and owners are needed to establish direct transmission in the setting of human infection.

\section{References}

1. Vandenesch F, Célard M, Arpin D, et al. Catheter-related bacteremia associated with coagulase-positive Staphylococcus intermedius. J Clin Microbiol 1995;33: 2508-10.

2. Boerlin P, Eugster S, Gaschen F, et al. Transmission of opportunistic pathogens in a veterinary teaching hospital. Vet Microbiol 2001;82:347-59.

3. Biberstein EL, Jang SS, Hirsh DC. Species distribution of coagulase-positive Sta-phylococci in animals. J Clin Microbiol 1984; 19:610-5.

4. Talan DA, Staatz D, Staatz A, et al. Staphylococcus intermedius in canine gingiva and canine-inflicted human wound infections: laboratory characterization of a newly recognized zoonotic pathogen. J Clin Microbiol 1989;27:78-81.

5. Douglas LG. Bite wounds. Am Fam Physician 1975;11:98-9

6. Feder HM, Shanley JD, Barbera JA. Review of 59 patients hospitalized with animal bites. Pediatr Infect Dis J 1987;6:24-8.

7. Goldstein EJC. Bite wounds and infection. Clin Infect Dis 1992;14:633-8.

8. Barnham M, Homes B. Isolation of CDC group M-5 and Staphylococcus intermedius from infected dog bites. J Infect 1992;25:332-4.

9. Talan DA, Goldstein EJ, Staatz D, Overturf GD. Staphylococcus intermedius: clinical presentation of a new human dog bite pathogen. Ann Emerg Med 1989;18:410-3.

10. Talan DA, Citron DM, Abrahamian FM, et al. Bacteriologic analysis of infected dog and cat bites. N Engl J Med 1999;340:85-92.

11. Lee J. Staphylococcus intermedius isolated from dog-bite wounds. J Infect 1994;29: 105.

12. Gerstadt K, Daly JS, Mitchell M, et al. Methicillin-resistant Staphylococcus intermedius pneumonia following coronary artery bypass grafting. Clin Infect Dis 1999;29:218-9.

13. Kempker R, Mangalat D, Kongphet-Tran T, Eaton M. Beware of the pet dog: a case of Staphylococcus intermedius infection. Am J Med Sci 2009;338:425-7.

14. Tanner MA, Everett CL, Youvan DC. Molecular phylogenetic evidence for noninvasive zoonotic transmission of Staphylococcus intermedius from a canine pet to a human. J Clin Microbiol 2000;38: 1628-31.

15. Pottumarthy S, Schapiro JM, Prentice JL, et al. Clinical isolates of Staphylococcus intermedius masquerading as methicillinresistant Staphylococcus aureus. J Clin Microbiol 2004;42):5881-4.

16. Kikuchi K, Karasawa T, Piao C, et al. Molecular confirmation of transmission route of Staphylococcus intermedius in mastoid cavity infection from dog saliva. J Infect Chemother 2004;10:46-8.

17. Atalay B, Ergin F, Cekinmez M, et al. Brain abscess caused by Staphylococcus intermedius. Acta Neurochir 2005;147:347-8.

18. Kelesidis T, Tsiodras S. Staphylococcus intermedius is not only a zoonotic pathogen, but may also cause skin abscesses in humans after exposure to saliva. Int J Infect Dis 2010;14:e838-41.

19. Hatch S, Sree A, Tirrell S, et al. Metastatic complications from Staphylococcus intermedius, a zoonotic pathogen. J Clin Microbiol 2012;50:1099-101.

20. Khambaty F, Bennet R, Shah D. Application of pulse-field gel electrophoresis to the epidemiological characterization of Staphylococcus intermedius implicated in a food-related outbreak. Epidemiol Infect 1994;113:75-81.

21. Devriese LA, Vancanneyt M, Baele M, et al. Staphylococcus pseudintermedius sp. nov., a coagulase-positive species from animals. Int J Syst Evol Microbiol 2005;55:1569-73.

22. Sasaki T, Kikuchi K, Tanaka Y, et al. Reclassification of phenotypically identified Staphylococcus intermedius strains. J Clin Microbiol 2007;45:2770-8.

23. Perreten V, Kadlec K, Schwarz S, et al. Clonal spread of methicillin-resistant Staphylococcus pseudintermedius in Europe and North America: an international multicentre study. J Antimicrob Chemother 2010;65:1145-54.

24. Fitzgerald JR. The Staphylococcus intermedius group of bacterial pathogens: species re-classification, pathogenesis and the emergence of methicillin resistance. Vet Dermatol 2009;20:490-5.

25. Versalovic J, ed. Manual of clinical microbiology. 10th ed. Washington, DC: ASM Press; 2011.

26. Decristophoris P, Fasola A, Benagli C, et al. Identification of Staphylococcus intermedius group by MALDI-TOF MS. Syst Appl 
Microbiol 2011;34:45-51.

27. Stegmann R, Burnens A, Maranta C, et al. Human infection associated with methicillin-resistant Staphylococcus pseudintermedius ST71. J Antimicrob Chemo 2010; 65:2047-8.

28. Riegel P, Jesel-Morel L, Laventie B, et al. Coagulase-positive Staphylococcus pseudintermedius from animals causing human endocarditis. Int J Med Micro 2011;301: 237-9.

29. Chuang C, Yang Y, Huseh P, et al. Catheterrelated bacteremia caused by Staphylococcus pseudintermedius refractory to antibiotic-lack therapy in a hemophilic child with dog exposure. J Clin Microbiol 2010;48:1497-8.

30. Van Hoovels L, Vankeerberghen A, Boel A, et al. First case of Staphylococcus pseudintermedius infection in a human. $\mathrm{J}$ Clin
Microbiol 2006;44:4609-12.

households. PLoS One 2011;6:e27788.

31. Ohara-Nemoto Y, Haraga H, Kimura S, Nemoto TK. Occurrence of staphylococci in the oral cavities of healthy adults and nasal oral trafficking of the bacteria. J Med Microbiol 2008;57:95-9.

32. Maggs A, Pennington T. Temporal study of staphylococcal species on the skin of human subjects in isolation and clonal analysis of Staphylococcus capitis by sodium dodecyl sulfate-polyacrylamide gel electrophoresis. J Clin Microbiol 1989;27: 2627-32.

33. Talan DA, Staatz D, Staatz A, Overturf GD. Frequency of Staphylococcus intermedius as human nasopharyngeal flora. J Clin Microbiol 1989;27:2393-4.

34. Laarhoven LM, de Heus P, van Luijn J, et al. Longitudinal study on methicillin-resistant Staphylococcus pseudintermedius in
35. Van Diujkeren E, Kamphuuis M, van der Mije, IC et al. Transmission of methicillinresistant Staphylococcus pseudintermedius between infected dogs and cats and contact pets, humans and the environment in households and veterinary clinics. Vet Microbiol 2011;150:338-43.

36. Paul NC, Moodley A, Ghibaudo G, Guardabassi L. Carriage of methicillinresistant Staphylococcus pseudintermedius in small animal veterinarians: indirect evidence of zoonotic transmission. Zoonoses Public Health 2011;58:533-9.

37. Guardabassi L, Loeber M, Jacobson A Transmission of multiple antimicrobialresistant Staphylococcus intermedius between dogs affected by deep pyoderma and their owners. Vet Microbiol 2004; 98:23-7. 